\title{
Hyperproliferative action of bovine papillomavirus: genetic and histopathological aspects
}

\author{
R.P. Araldi'1,2, T.C. Melo ${ }^{1,3}$, A.C. Neves ${ }^{1}$, D.D. Spadacci-Morena ${ }^{4}$, R.F. Magnelli', \\ D.G. Modolo', P.L. de-Sá-Júnior ${ }^{1}$, J. Mazucchelli-de-Souza ${ }^{1,2}$, R.F. Carvalho ${ }^{1}$, \\ W. Beçak ${ }^{1}$ and R.C. Stocco ${ }^{1}$ \\ ${ }^{1}$ Laboratório de Genética, Instituto Butantan, São Paulo, SP, Brasil \\ 2Programa de Pós-Graduação Interunidades em Biotecnologia, \\ Universidade de São Paulo, São Paulo, SP, Brasil \\ ${ }^{3}$ Programa de Pós-Graduação em Morfologia Funcional e Estrutural, \\ Escola Paulista de Medicina, Universidade Federal de São Paulo, \\ São Paulo, SP, Brasil \\ ${ }^{4}$ Laboratório de Fisiopatologia, Instituto Butantan, São Paulo, SP, Brasil \\ Corresponding author: R.C. Stocco \\ E mail: rita.stocco@butantan.gov.br
}

Genet. Mol. Res. 14 (4): 12942-12954 (2015)

Received March 26, 2015

Accepted July 10, 2015

Published October 21, 2015

DOI http://dx.doi.org/10.4238/2015.October.21.15

ABSTRACT. The bovine papillomavirus (BPV) causes papillomas that regress spontaneously, but can also progress to malignancy. This study evaluated the role of BPV in oncogenesis. Twenty-four samples from uninfected calves and the papillomas of BPV infected cattle were subjected to molecular diagnosis, as well as histopathological and immunohistochemical analyses. The comet assay (CA) was used to evaluate the clastogenic potential of BPV. The results confirmed the presence of BPV-2, 3, 5, and 9 in infected samples. Histopathological analysis revealed acanthosis, koilocytosis, hypergranulosis, hyperkeratosis, and transformed fibroblasts. E7 and L1 BPV proteins were detected in the epithelium, as well as in the connective tissues, indicating productive infection at different sites. CA 
results showed that BPV-2, 5, and 9 exhibit the same level of clastogenicity. These findings support the oncogenic action of BPV in establishing a favorable microenvironment for oncogenesis.

Key words: Bovine papillomavirus; Viraloncogenesis; Histopathology; Immunodetection; Comet assay

\section{INTRODUCTION}

Bovine papillomavirus (BPV) is the etiological agent of bovine papillomatosis, an infectious disease characterized by the presence of benign lesions. The disease not only affects the skin and mucosal tissue, but can also result in cancers (Stocco dos Santos et al., 1998). BPV can be found worldwide, and its dispersion can occur via direct or indirect contact between infected animals or through contact with contaminated areas, such as milking machines, water dispensers, feeders, ropes or fences, or transmitted by insects (Love et al., 2012).

BPV infection starts from a micro-injury, which exposes the peptidoglycan of heparin sulfate present in the plasma membrane (McBride et al., 2012). The infection begins in the basal layer of the epithelium, where the viral genome isepisomal, maintained at a low copy number (McBride et al., 2012), and dependent on cellular differentiation of the keratinocytes (McBride et al., 2012).

Currently there are 13 types of BPV described in the literature. However, this number may exceed 20 (Lunardi et al., 2013). BPVs are divided into three genera: Deltapapillomavirus (BPV-1, 2, and 13), Epsilonpapillomavirus (BPV-5 and 8), and Xipapillomavirus (BPV-3, 4, 6, 9, 10, 11, and 12). BPV-7, however, does not identify with a specific genre (Melo et al., 2014). The Deltapapillomavirus can also cause equine sarcoids (Lunardi et al., 2013) and fibropapillomas (Burnett et al., 1992). BPV is also associated with bladder and esophagus cancer (Bocaneti et al., 2014).

BPVs have a circular genome of $8 \mathrm{~kb}$ (Baker et al., 1987). The genome consists of doublestranded DNA associated with histone-like proteins (Leto et al., 2011), that are further surrounded by a icosahedral capsid (Baker et al., 1987). The genome of these oncogenic viruses is divided into three regions: early (E), long (L), and late control region (LCR) (Bocaneti et al., 2014). The $E$ region composes $50 \%$ of the viral genome, with approximately $4000 \mathrm{bp}$, and encodes the E1, E2, E4, E5, E6, and E7 proteins (Zheng and Baker, 2006). The L region occupies $40 \%$ of the genome, with approximately $3000 \mathrm{bp}$, and contains the L1 and L2 open reading frames (ORFs) that encode the capsid proteins. The LCR occupies $10 \%$ of the genome, with approximately $1000 \mathrm{bp}$, which contains the origin of replication and the binding sites for multiple transcription factors (Bocaneti et al., 2014).

The E5, E6, and E7oncoproteins are involved in several steps of cell transformation, including cytogenetic aberrations and clastogenic action. This leads to genomic instability, which is directly associated with malignancy (Stocco dos Santos et al., 1998; Melo et al., 2011; Araldi et al., 2013). Studies show that the E2 protein regulates DNA replication and acts as a transcriptional inhibitor of E6 and E7 (McBride et al., 2012). It was also demonstrated that the methylation of dinucleotides CpGs, verified as present in the E2 binding site, leads to inhibition of E2 transcription, resulting in E6 and E7 transcriptional activation (Kim et al., 2003). Although the oncogenic potential of BPVs is well known, the carcinogenic mechanisms of these viruses are not completely understood. It is also known that the oncogenic process is initiated after years or decades of mutations (Araldi et al., 2013). This study therefore evaluated the presence of BPV sequences in skin papillomas, which were then typified through sequencing. The samples were also submitted for differential diagnosis via histopathological analysis. The expression of the E7 
oncoprotein and L1 structural protein was analyzed in both the epithelium and stroma through immunohistochemistry of paraffin embedded samples (IHC-P). We also analyzed the level of clastogenicity of BPV in situ (papillomas), as an indicator of viral activity. The results suggest a role for BPV in the development of a favorable microenvironment for cell hyperproliferation and oncogenesis. This suggests that the virus can induce malignancy without the need for co-factors such as the bracken, Pteridium aquilinum.

\section{MATERIAL AND METHODS}

\section{Sample collection and histopathological analysis}

Twenty-four samples were collected: six from the skin of BPV-free calves, aged 6-8 months (controls), 18 skin papillomas were obtained from cattle (Bos taurus, Simmental), aged 2-5 years. The samples were collected by a veterinarian, using local anesthesia ( $2 \%$ lidocaine). The Ethics Committee on Animal Use at the Butantan Institute approved the methodology used in this study (process No.: 1035/13).

Samples were divided into three portions for various analyses: 1) BPV molecular identification and typing, 2) histopathology and IHC-P, and 3) comet assay (CA). The samples designed for histopathology and IHC-P were fixed in 10\% formalin, dehydrated in increasing concentrations of ethanol, embedded in paraffin, and cut in 4- $\mu \mathrm{m}$ sections. For the histopathological analysis, the material was stained with hematoxylin-eosin. The slides were analyzed under a binocular optical microscope Axiophot (Carl Zeiss, Germany), under the 5, 10, 20, and 40X objective lenses, and images were captured using the AxioVision software version 4.7.2. (Carl Zeiss). Skin tissue fragment obtained from a BPV-free calf served as the negative control for histopathological analysis.

\section{BPV molecular identification and typing}

DNA was extracted using the Illustra Cell \& Tissue Mini Spin GenomicPrep Kit (GE Healthcare, Buckinghamshire, UK), according to the manufacturer instructions. The extracted DNA was quantified using a spectrophotometer (BioPhotometer Plus, Eppendorf, Hamburg, Germany), and the quality and integrity of the DNA were evaluated by polymerase chain reaction (PCR), using the bovine $\beta$-globin primer (forward 5'-CTCTTTGTTCACAACAAAGAG-3' and reverse 5'-CAGATGAACCTTCCACTGAGC-3') according to Yaguiu et al. (2008).

BPV identification was performed by PCR, using the degenerate primer pairs Delta-Epsilon (forward 5'-CCAGAYTAYYTMAAAATGGC-3' and reverse 5'-ATAAMKGCTAGCTTATATTC-3') and Xi (forward 5'-TWYAATAGDCCVTTTTGGAT-3' and reverse 5'-TTMCGCCTACGCTTTGGCGC-3'). These primers were designed based on the sequence homology of the L1 ORF, resulting in amplicons of 430 and $600 \mathrm{bp}$, respectively (Araldi et al., 2014). The PCR was performed in $50 \mu \mathrm{L}$ total volume, composed of $36 \mu \mathrm{L}$ PCR Master Mix (Quatro G, Porto Alegre, RS, Brazil), $2 \mu \mathrm{L}$ forward primer, $2 \mu \mathrm{L}$ reverse primer, and $10 \mu \mathrm{L} 200 \mathrm{ng} / \mu \mathrm{L}$ DNA template. Reactions were carried out in a Veriti 96 Well Thermal Cycler (Applied Biosystems, Singapore), based on the following cycles: an initial $10 \mathrm{~min}$ phase at $94^{\circ} \mathrm{C}, 35$ cycles for $1 \mathrm{~min}$ at $94^{\circ} \mathrm{C}$ (denaturation), $1 \mathrm{~min}$ at $52^{\circ} \mathrm{C}$ (annealing), $1 \mathrm{~min}$ at $72^{\circ} \mathrm{C}$ (extension), and a final $10-\min$ step at $72^{\circ} \mathrm{C}$. Copies of the viral genomes of BPV-2 (M20219.1) and BPV-4 (X05817.1), previously cloned into the bacterial vector PAT153, were used as reaction positive controls. The resulting PCR products were analyzed on $2 \%$ agarose gel in TAE 
buffer, stained with $1 \%$ GelRed (Biotium, Hayward, CA, USA). Electrophoresis was performed in a Horizon 20:25 vat (Life Technologies, Carlsbad, CA, USA) at $100 \mathrm{~V}$ and $400 \mathrm{~mA}$ for $120 \mathrm{~min}$. A 100-bp DNA Ladder was used (Invitrogen, Carlsbad, CA, USA). The gel was visualized on a transilluminator MiniBIS Pro (DNR Bio-Imaging Systems, Jerusalem, Israel) and the images were recorded using the GelCapture version 7.1 software (DNR Bio-Imaging Systems).

Amplicons were purified using the PureLink Quick Gel Extraction Kit (Invitrogen), according to manufacturer instructions. The purified amplicons $(5 \mu \mathrm{L})$ were subjected to sequencing reactions on the ABI PRISM 3730 DNA Analyzer (Applied Biosystems, Singapore), using the BigDye Terminator v3.1 Cycle Sequencing Kit (Applied Biosystems, Carlsbad, CA, USA) and $2.5 \mu \mathrm{L} 5$ pm respective primers. For in silico analysis, the quality of the DNA sequences was checked, and overlapping fragments were assembled using the BioEdit software version 7.0.9.0 (Ibis Therapeutics, Carlsbad, CA, USA). Sequences were compared using the BLASTn program of the National Center of Biotechnology (NCBI) database (http://blast.ncbi.nlm.gov).

\section{Immunodetection of L1 and E7 proteins via IHC-P}

Sections were deparaffinized and subjected to antigen retrieval in $0.01 \mathrm{M}$ citrate buffer at $95^{\circ} \mathrm{C}$ for $35 \mathrm{~min}$. IHC-P was performed using the EnVision ${ }^{\mathrm{TM}}+$ HRP System (Dako, Carpinteria, CA, USA). Endogenous peroxidase was blocked with the peroxidase block, included in the kit, for 10 min. Sections were washed 3 times with TBS (50 mM Tris- $\mathrm{HCl}, 150 \mathrm{mM} \mathrm{NaCl}, \mathrm{pH} 7.6$ ) for 5 min and treated with $0.01 \%$ Triton X-100 for $20 \mathrm{~min}$. The sections were washed for 5 min with TBS and blocked with 5\% BSA for 40 min. Monoclonal antibodies (mAbs) against L1 and E7 of HPV16 (Abcam, 25-50 $\mu \mathrm{L}$ ) were then added to sections at a 1:100 dilution, and incubated overnight at $4^{\circ} \mathrm{C}$ in a humid chamber. The anti-L1 mAb recognizes the structural protein $\mathrm{L} 1$, and its detection indicates viral assembly and productive infection (Nasir and Reid, 1999), whereas the anti-E7 mAb identifies the oncoprotein E7, which is present in all BPVs genres. These mAbs are frequently used for BPV and HPV detection (Day et al., 2003).

Slides were washed twice with TBS-T (TBS, 0.2\% Tween-20) following the incubation. Two drops (approximately $100 \mu \mathrm{L}$ ) of the secondary antibody, conjugated to a peroxidase labeled polymer was then added to the sections and incubated for $1 \mathrm{~h}$ at $4^{\circ} \mathrm{C}$ in a humidified chamber. Sections were washed three times with TBS-T for $5 \mathrm{~min}$ and treated with two drops of the chromogenic substrate 3-amino-9-ethylcarbazole 1 for $15 \mathrm{~min}$. Slides were then washed in distilled water for $5 \mathrm{~min}$ and counter stained with Mayer-hematoxylin for $3 \mathrm{~min}$. They were then rinsed with distilled water and dipped in $0.037 \mathrm{M}$ ammonium hydroxide solution to remove excess hematoxylin. Slides were then mounted with Faramount mounting medium (Dako) and analyzed using a binocular light microscope Axiophot (Carl Zeiss) under the 10X, 20X, and 40X objective lenses. Images were captured using the AxioVision software version 4.7.2. (Carl Zeiss). A fragment of skin tissue from a BPV-free calf (experimental control) and a fragment of papilloma without the addition of primary antibody (reaction control) were used.

\section{Comet assay}

Slides were immersed in $1.5 \%$ normal melting point agarose (Top Vision, Fermentas, Vilnius, Lithuania) diluted in PBS at $60^{\circ} \mathrm{C}$, and then kept overnight at room temperature for drying.

The fragments of cutaneous papillomas for the CA were stored at $-80^{\circ} \mathrm{C}$ to avoid possible damage from physical shearing of the DNA due to the formation of ice crystals. Papillomas (100 mg) 
were homogenized in $1 \mathrm{~mL}$ Hank's Balanced Salt Solution (Gibco, Carlsbad, CA, USA) containing $20 \mathrm{mM}$ EDTA, $10 \%$ DMSO, and $5 \%$ trypsin at $4^{\circ} \mathrm{C}$, using a mechanical homogenizer (Ultra 80 , Ultra Stirrer) at $8000 \mathrm{rpm}$. A $10-\mu \mathrm{L}\left(10^{4}\right.$ cells) aliquot of the homogenate was added to $75 \mu \mathrm{L} 0.75 \%$ low melting point agarose (Top Vision, Fermentas) diluted in PBS at $37^{\circ} \mathrm{C}$. The mixture $(85 \mu \mathrm{L})$ was then transferred to pre-covered slides (covered with cover slips) and allowed to incubate for 20 $\min$ at $4^{\circ} \mathrm{C}$. After incubation, the coverslips were removed and immersed in lysis solution $(2.5 \mathrm{mM}$ $\mathrm{NaCl}, 100 \mathrm{mM}$ EDTA, $10 \mathrm{mM}$ Tris- $\mathrm{HCl}, 1.1 \%$ Triton X-100, and $11.2 \%$ DMSO) at $4^{\circ} \mathrm{C}$ for $2 \mathrm{~h}$. The next steps were done in the dark to prevent the induction of DNA damage.

Slides were washed with PBS, placed in a horizontal electrophoresis vat, covered with buffer solution ( $300 \mathrm{mM} \mathrm{NaOH}$ and $1 \mathrm{mM}$ EDTA, $\mathrm{pH}>13.0$ ), and allowed to incubate for $40 \mathrm{~min}$ at $4^{\circ} \mathrm{C}$. The electrophoresis conditions were as follows: $25 \mathrm{~V}(0.86 \mathrm{~V} / \mathrm{cm})$ and $300 \mathrm{~mA}$ for 20 min. This step promotes the migration of the free DNA fragments of the nucleus. The slides were then washed three times with neutralizing buffer ( $400 \mathrm{mM}$ Tris- $\mathrm{HCl}, \mathrm{pH} 7.5)$, in $5 \mathrm{~min}$ intervals. The samples were fixed in absolute ethanol and stained with $20 \mu \mathrm{L}$ propidiumiodide $(4 \mathrm{mg} / \mathrm{mL})$. The analysis was performed using an epifluorescence microscope equipped with a $510-560 \mathrm{~nm}$ excitation filter and a 590-nm barrier filter, at a total magnification of 400X. A total of 100 cells per slide were analyzed and classified into various classes depending on the amount of DNA damage: class 0 (without DNA damage) to 4 (highest level of damage), according to the size of the tail. Statistical analyses were performed based on the scores obtained from the sum of the product of the number of cells observed by the respective class value. Skin fragments from six BPV-free calves served as negative controls, and were subjected to the same conditions as those infected.

\section{Statistical analysis}

The Mann-Whitney U-test was performed for comparison between uninfected and infected bovines. The Kruskal-Wallis test, followed by the Dunn test, was performed for comparing the clastogenic potential of the different viral types identified in this study. Tests were performed using the BioEstat software version 5.3, with a significance level of $5 \%$.

\section{RESULTS}

\section{BPV molecular identification and typing}

BPV identification analyses revealed the absence of viral infection in six calves, which were used as negative controls, and BPV infection in 18 adult animals. BPV typing demonstrated the presence of BPV-2 in 5, BPV-3 in 1, BPV-5 in 8, and BPV-9 in 3 bovines. We also observed the presence of the putative new virus type, BR/UEL2.

\section{Histopathological analysis}

We observed the presence of papillomas at anatomical sites that were more susceptible to physical attrition (Table 1), such as the dewlap and dorsal areas. Comparison of the normal skin (control) with the papilloma demonstrated a reduction in epidermal attachments (Figure 1). BPV can be maintained in latency and be asymptomatic, therefore we submitted the normal tissue for molecular BPV identification. However, the virus was not detected in these samples. The histopathological analysis indicated the presence of koilocytosis, ortho and parakeratotic 
hyperkeratosis, hypergranulosis in granular layer and acanthosis, suggesting a cytopathic action of BPV (Figure 1). Samples infected by BPV-2 (Deltapapillomavirus) and BPV-5 (Epsilonpapillomavirus) were classified as fibropapillomas, based on characterization of the fibroblastic stroma, which is shown as a fascicular disposition of fibroblasts (Figure 2). The presence of atypical and anaplastic fibroblasts in the dermal-epidermal junction was also observed (Figure 1).

\begin{tabular}{|c|c|c|c|c|c|c|c|c|c|}
\hline \multirow[t]{2}{*}{ Animal } & \multirow[t]{2}{*}{ Virus type } & \multirow[t]{2}{*}{ Sequence identity } & \multirow[t]{2}{*}{ Sample localization } & \multicolumn{5}{|c|}{ Class of comets } & \multirow[t]{2}{*}{ Score } \\
\hline & & & & 0 & 1 & 2 & 3 & 4 & \\
\hline 01 & Unidentified & - & Thorax & 89 & 7 & 1 & 2 & 1 & 19 \\
\hline 02 & Unidentified & - & Thorax & 76 & 7 & 7 & 9 & 1 & 52 \\
\hline 03 & Unidentified & - & Thorax & 74 & 12 & 1 & 11 & 2 & 55 \\
\hline 04 & Unidentified & - & Thorax & 90 & 5 & 3 & 2 & 0 & 17 \\
\hline 05 & Unidentified & - & Thorax & 87 & 5 & 1 & 5 & 2 & 30 \\
\hline 06 & Unidentified & - & Thorax & 86 & 10 & 2 & 1 & 1 & 21 \\
\hline 07 & BR/UEL2 & $90 \%$ & Thorax & 2 & 0 & 2 & 19 & 77 & 369 \\
\hline 08 & BPV-2 & $98 \%$ & Nose & 5 & 0 & 0 & 20 & 75 & 360 \\
\hline 09 & BPV-2 & $92 \%$ & Dewlap & 16 & 6 & 10 & 22 & 46 & 270 \\
\hline 10 & BPV-2 & $95 \%$ & Dewlap & 4 & 7 & 17 & 29 & 43 & 300 \\
\hline 11 & BPV-2 & $98 \%$ & Dewlap & 10 & 31 & 4 & 15 & 40 & 244 \\
\hline 12 & BPV-2 & $97 \%$ & Dorsal & 16 & 0 & 1 & 10 & 73 & 324 \\
\hline 13 & BPV-3 & $95 \%$ & Dewlap & 3 & 2 & 2 & 12 & 81 & 366 \\
\hline 14 & BPV-5 & $92 \%$ & Thorax & 0 & 0 & 6 & 10 & 84 & 378 \\
\hline 15 & BPV-5 & $90 \%$ & Dorsal & 2 & 1 & 4 & 12 & 81 & 369 \\
\hline 16 & BPV-5 & $98 \%$ & Nose & 1 & 1 & 5 & 15 & 78 & 368 \\
\hline 17 & BPV-5 & $94 \%$ & Dorsal & 0 & 1 & 8 & 9 & 82 & 372 \\
\hline 18 & BPV-5 & $98 \%$ & Nose & 0 & 1 & 9 & 16 & 74 & 363 \\
\hline 19 & BPV-5 & $90 \%$ & Dorsal & 0 & 0 & 1 & 10 & 89 & 388 \\
\hline 20 & BPV-5 & $92 \%$ & Thorax & 0 & 0 & 10 & 7 & 83 & 373 \\
\hline 21 & BPV-5 & $92 \%$ & Thorax & 0 & 0 & 7 & 14 & 79 & 372 \\
\hline 22 & BPV-9 & $77 \%$ & Dewlap & 0 & 0 & 0 & 11 & 89 & 389 \\
\hline 23 & BPV-9 & $80 \%$ & Thorax & 0 & 3 & 0 & 5 & 92 & 386 \\
\hline 24 & BPV-9 & $92 \%$ & Dorsal & 3 & 4 & 7 & 5 & 81 & 357 \\
\hline
\end{tabular}
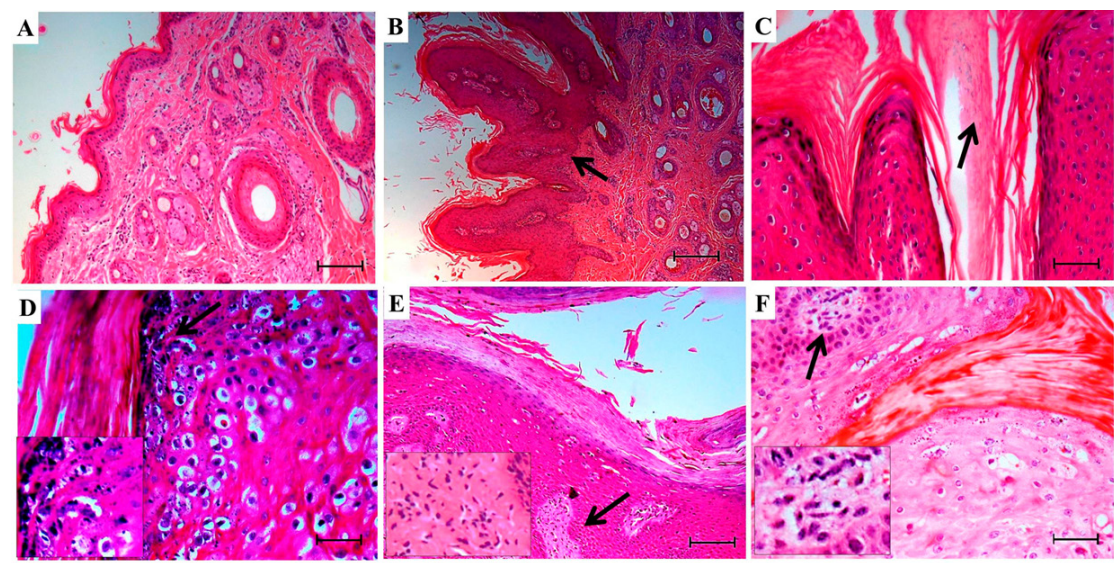

Figure 1. Histopathological analysis using H\&E stainning. A. Normal skin with epidermal attachments, objective of 5X. B. Papilloma infected by BPV-9, showing acanthosis (arrow), objective of 10X. C. Parakeratotic hyperkeratosis, indicating a high mitogenic activity, objective of 10X. D. Hypergranulosis (arrow), objective of 10X and 40X. E. Normal fibroblasts into dermis, objective of 10X and 40X. F. Transformed fibroblasts in dermis epidermal junction, objective of $10 \mathrm{X}$ and $40 \mathrm{X}$. Scale bar of $100 \mu \mathrm{m}$. 


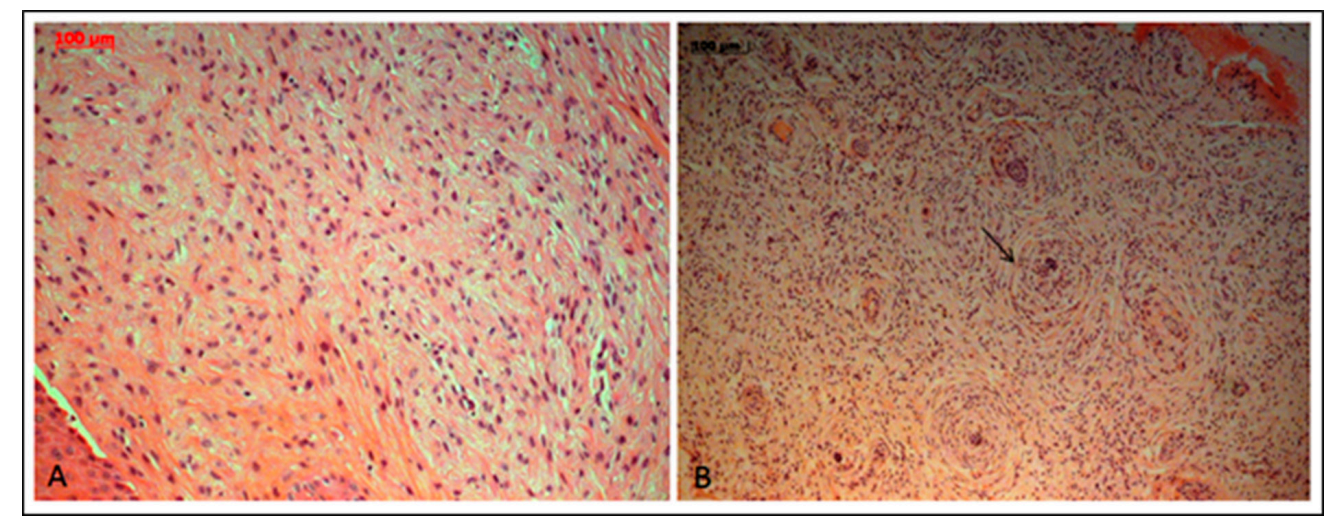

Figure 2. Difference between papilloma and fibropapilloma. Stroma of papilloma infected with BPV-3 (A) and fibroblastic stroma of fibropapilloma infected with BPV-2 (B), showing fibroblasts organized in fasciculus (arrow).

\section{Immunohistochemistry analysis}

To confirm the BPV presence in connective tissue, IHC-P was performed using mAbs against the early protein (E7) and the structural protein (L1). L1 is present in all genera of BPV, and its expression indicates viral assembly. The E7 oncoprotein was detected in both the epithelium and dermis, including endothelium tissue, but it was not detected in the experimental and reaction controls (Figure 3). The L1 protein was detected in the most differentiated layers of the epithelium (spinous and granularlayer), as well as in the dermis-epidermal junction (Figure 3).

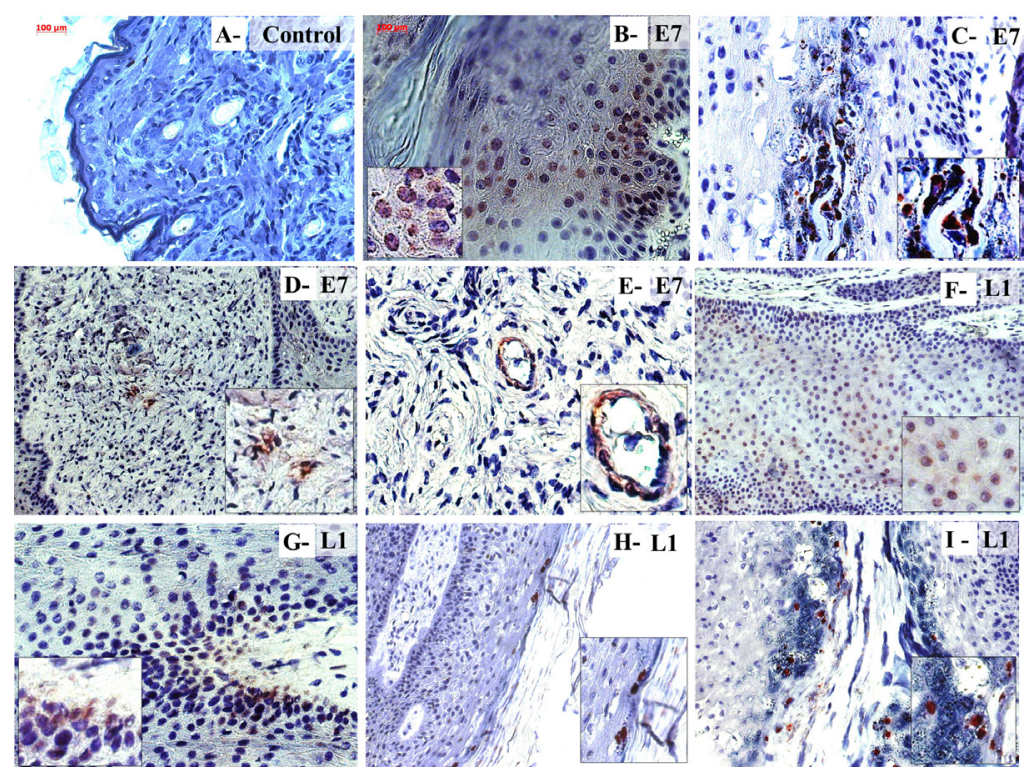

Figure 3. Immunohistochemical analysis. A. Normal skin showing absence of labeling (control), objective of $5 \mathrm{X}$. Immunodetection of E7 oncoprotein in epithelium, showing labeling in basal and spinous layer (B and $\mathbf{C}$ ), dermis, into fibroblasts (D) and endothelium of blood vessel (E), objectives of 20 and 40X. Immunodetection of L1 structural protein in spinous layer (F), dermis epidermal junctions (G), and granular layer ( $\mathbf{H}$ and $\mathbf{I})$, objectives of 20 and $40 \mathrm{X}$. 


\section{Comet assay}

To the best of our knowledge, this is the first study utilizing the comet assay to evaluate the clastogenic action of BPV in papillomas. A Kruskal-Wallis test with $5 \%$ significance level was performed using nucleoid tail length (Figure 4) and classification scores (Table 1) as measurements for DNA damage. The results demonstrated statistical differences between samples from the skin of BPV-free calves and papillomas $(\mathrm{H}=17.4326, \mathrm{P}=0.0006)$. The Dunn post hoc test demonstrated a clastogenic effect in all papilloma samples (Table 2). The test, however, did not show any differences in clastogenicity level among the BPV types 2, 5, and 9. This indicates that these virus types are able to induce DNA breaks, resulting in genomic instability, as result of oncoproteins that induce entry into the $S$ phase of the cell cycle. It was not possible to compare the clastogenic action of BPV-3 and the new putative virus type BR/UEL2 due to a limited number of samples with these viruses (at least three samples are preferred for proper statistical analysis).

Table 2. Result of the Dunn post-hoc test, showing significative statistical differences between normal skin of BPVfree and papillomas.

\begin{tabular}{lccc}
\hline Normal skin (controls) & \multicolumn{3}{c}{ Papillomas } \\
\cline { 2 - 4 } & BPV-2 & BPV-5 & $378^{\mathrm{b}}$ \\
\hline $19^{\mathrm{a}}$ & $360^{\mathrm{b}}$ & $369^{\mathrm{b}}$ & $389^{\mathrm{b}}$ \\
$52^{\mathrm{a}}$ & $270^{\mathrm{b}}$ & $368^{\mathrm{b}}$ & $386^{\mathrm{b}}$ \\
$55^{\mathrm{a}}$ & $300^{\mathrm{b}}$ & $372^{\mathrm{b}}$ & $357^{\mathrm{b}}$ \\
$17^{\mathrm{a}}$ & $244^{\mathrm{b}}$ & $363^{\mathrm{b}}$ & - \\
$30^{\mathrm{a}}$ & $324^{\mathrm{b}}$ & $388^{\mathrm{b}}$ & - \\
$21^{\mathrm{a}}$ & - & $373^{\mathrm{b}}$ & - \\
- & - & $372^{\mathrm{b}}$ & - \\
- & - & - \\
\hline
\end{tabular}

Numbers followed by the same letters indicate absence of significative statistical valor.
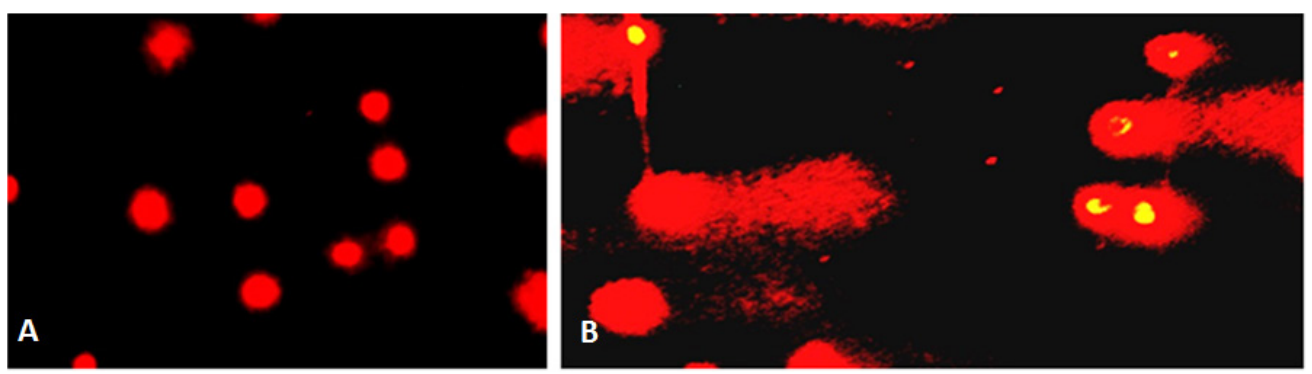

Figure 4. Evaluation of BPV activity in tissue through comet assay. A. Nucleoid class 0 (without DNA damage) observed in normal skin of calf uninfected by BPV. B. Nucleoid class 4 (indicating maximum DNA damage) observed in papilloma infected with BPV-2. Images obtained in a total magnification of $400 \mathrm{X}$.

\section{DISCUSSION}

\section{Molecular diagnosis and histopathological and immunohistochemical analysis}

We have studied the herd from which samples were obtained for the present study for the last 3 years, and have observed similar results to those reported in the literature (Araldi et al., 2013; 
Melo et al., 2014). A high incidence of cutaneous papillomatosis was observed in the herd studied, mainly in younger bovines of 2-3 years of age. Approximately $60 \%$ of Brazilian herd are infected with BPV (Stocco dos Santos et al., 1998). This is due to the great expansion of herds in Brazil over the last few decades without specific concern for the clinical consequences of BPV infection. However, this situation is not uncommon worldwide.

Although our molecular typing demonstrated the presence of BPV-2 in five animals, we did not observe clinical symptoms of bladder cancer, such as enzootic hematuria. This may be justified by the absence of the bracken fern $P$. aquilinum in the farm. The absence of this bracken was an eligibility requirement for our study, since the bracken has been shown to present carcinogenic and clastogenic compounds, such as Quercetin, which can induce false positive results in the comet assay (Stocco dos Santos et al., 1998).

Considering specific situations in which clinical signs that suggest malignance could not be observed, BPV infection could cause cytogenetic aberrations, leading to genomic instability and cancer (Stocco dos Santos et al., 1998; Melo et al., 2011). The bovine lifetime is long enough to allow cancer to arise from years of accumulated mutations.

In relation to the distribution papillomas in the body, the disease was concentrated in regions more susceptibleto physical attrition, such as the dewlap and dorsal areas. These sites are in direct contact with fences, trunks, feeders, and drinkers. Therefore, the data reinforces the concept that microinjuries are necessary for the initiation of BPV infection, since they provide a means for the virus to make contact with the heparan sulfate of basal cells, thus infecting the epithelium basal layer (McBride et al., 2012). This tissue injury is also required for the initiation of equine sarcoids (Martens et al., 2000). The presence of papillomas in areas exposed to attrition reinforce the new method of BPV infection, in which the peripheral blood acts not only as a virus reservoir, but also as a disseminator vehicle for other tissues (Stocco dos Santos et al., 1998; Araldi et al., 2013). Several studies have reported the presence of BPV in CD4+ and CD8+T-lymphocytes (Roperto et al., 2011), as well as its activity in peripheral blood, as determined by the comet assay (Araldi et al., 2013). Furthermore, it is known that peripheral blood mononuclear cells (PBMCs) are sites of productive BPV infection (Roperto et al., 2011).

It is known that the spontaneous regression of papillomas is characterized by lymphocytic infiltration in the dermis, with a predominance of $\mathrm{CD}^{+}, \mathrm{CD}^{+}$, and $\gamma \delta \mathrm{T}$-lymphocytes. However, at the same time that papilloma regression is occurring, new virus can be carried to the epithelium, leading to disease relapse.

Although it is known that the papillomavirus causes morphologic alterations associated with a cytopathic effect, which is detectable through biopsies, there are few histopathological studies involving BPV. This highlights the importance of the current study, which provides additional data to improve our understanding of the mechanisms associated with viral pathogenesis and oncogenesis. The histopathological analysis showed koilocytosis, acanthosis, hypergranulosis, and both ortho and parakeratotic hyperkeratosis in all samples.

Acanthosis is defined as hyperplasia of the suprabasal layer with an increase in desmosomes and tonofibrils (Lancaster and Olson, 1982). Acanthosis in the analyzed bovine papilloma samples could be caused by the mitogenic action of the E6 and E7 oncoproteins that stimulate entry into the $S$ phase of the host cell, thus providing polymerases for BPV replication. The E6 oncoprotein forms a complex with E6AP, resulting in p53 inactivation, and at the same time, interacts with the histone acetyltransferase CBP/p300 complex, thus reducing polymerase affinity to the TP53 promoter (Zimmermann et al., 1999). These mechanisms prevent cell cycle 
arrest in the G1 phase. The E7 oncoprotein induces phosphorylation of the pRb tumor suppressor protein (White and Howley, 2013), resulting in translocation of the E2F transcription factor from the cytoplasm to the nucleus, where it stimulates entry into the S phase (White and Howley, 2013).

Koilocytosis is commonly identified histopathological analyses of papillomas in different organisms, including canines (Bianchi et al., 2012) and humans (Betiol et al., 2012; Rogovskyy et al., 2012). Koilocytes are degenerated keratinocytes that are destined for cell death or epithelium release. These cells are characterized by the presence of a prominent halo, which does not stain with eosin or Schiff's periodic acid, as well as an acentric and pyknotic nucleus. Koilocytes were observed in most differentiated layers of the epithelium, where a significant amount of virions can also be found. Although the pathways involved in koilocyte formation are unknown, it is believed that they can contribute to the instability of keratinocytes, thus facilitating the release of virus particles to the environment (Krawczyk et al., 2008).

Hypergranulosis is characterized by the presence of a large quantity of keratohyalin in the granular layer. It has also been described in canine (Fernandes et al., 2009), rabbit (Rashad and Evans, 1967) and human papillomas (Martelli-Marzagão et al., 2010). Keratohyalin granules are rich in sulfur amino acids, which are associated with the keratinization process, resulting in hyperkeratosis, which was observed in all analyzed papilloma samples.

Parakeratotic hyperkeratosis is indicative of tissue hyper-differentiation, and is a common finding associated with papillomavirus infection (Martelli-Marzagão et al., 2010). Hyperkeratosis is a result of mitogenic stimulation induced by BPV oncoproteins, which is associated with the absence of phosphatases and oxidases.

Although BPV has been reported to exhibit epithelium tropism, we analyzed the connective tissue of papillomas, and observed the presence of pleomorphic and anaplastic fibroblasts closer to the basal layer (Figure 1), suggesting fibroblastic transformation. Similar findings were also observed in fibropapillomas of giraffes infected with BPV (Williams et al., 2011), feline sarcoids (Teifke et al., 2003), and cattle fibropapillomas (Campo, 1997). It is known that Deltapapillomavirus genus affects both the epithelium and mesenchyme (Roperto et al., 2012). Transformed fibroblasts were identified in both papillomas and fibropapillomas and in samples infected by BPV-2, 5, and 9, and were therefore infected by all genera.

Fibroblastic transformation may be the result of the synergic action of E5 and E6 oncoproteins. E5 is localized to the internal membrane of the endoplasmic reticulum and Golgi complex, and facilitates immune evasion via sequestration of MHC-I molecules (Tomita et al., 2007) as well as promotes cellular transformation (Roperto et al., 2012). However, E6 links to paxillin, resulting in a transformed phenotype (Moody and Laimins, 2010).

Cell cycle regulation in mammals is controlled by the ordered activation of cyclin dependent kinases (CDKs). Rearrangement of CDK complexes and p21 degradation occur in transformed fibroblasts infected with BPV, resulting in a mitogenic stimulus.

In order to confirm BPV infection in fibroblasts, we performed IHC-P using mAbs against the E7 and L1 proteins. E7 was detected in all epithelial layers. E7 is responsible for pRb phosphorylation, resulting in entry into the S phase of the cell cycle (White and Howley, 2013). E7 was also detected in the basal layer, closer to the transformed fibroblasts, as well as in connective tissue. E7 detection is an indicator of the presence of virus in the dermis.

L1 protein was observed in the basal cells of the epithelium and in connective tissue. This data suggests virus activity at another sites besides the epithelium. Although the literature supports the paradigm of cell differentiation dependent gene expression, current studies have identified 
the presence of L1 of BPV and HPV at other sites, including the placenta (Roperto et al., 2012), trophoblastic cells, and blastocysts (Calinisan et al., 2002).

Although several studies have demonstrated a role for BPV in cancer etiology (Roperto et al., 2012; Bocaneti et al., 2014; Potocki et al., 2014), whether papillomas can progress to cancer in the absence of environmental factors such as the presence of $P$. aquilinum is still unknown. In this study, we verified that BPV affects both the epithelium and connective tissue. We also report, using the comet assay, that BPV infection results in chromosomal aberrations (Stocco dos Santos et al., 1998; Melo et al., 2011) and DNA breaks in PBMCs, indicating virus activity in these cells (Araldi et al., 2013).

This is the first time that the comet assay has been used to analyze the clastogenic action of BPV in papilloma tissue. This allows for a better discussion of the role of papillomavirus oncogenes in the establishment of a tumor microenvironment. We observed increased numbers of class 4 nucleoids as well as hedgehog comets in papilloma samples. The Dunn test showed significant statistical differences between skin samples from BPV and papilloma free calves and papilloma samples. However, there were no differences among BPV types 2, 5, and 9, indicating that the three genres of BPV display similar clastogenic potential.

We conclude that the clastogenicity observed in this study is due to BPV infection, based on the fact that the negative controls were exposed to the same environmental conditions as infected cattle with papillomatosis. Samples were kept at $-80^{\circ} \mathrm{C}$ to avoid DNA damage caused by physical DNA shearing. All samples were subjected to the same conditions of cellular dissociation, using mechanical and enzymatic techniques. Studies have shown that any form of cellular dissociation is associated with DNA damage (Hartmann et al., 2003). Moreover, similar to samples exposed to opportunistic infections, the samples analyzed did not show any physical injuries, thereby reducing false-positive results.

The high frequency of hedgehog comets, characterized by a small or absent head and a long tail, indicates elevated DNA fragmentation due to single and double strand breaks. The quantification of these comets was only possible by visually counting, because automated systems, based on computational programs, classify hedgehog comets as class 0 . These programs are not able to identify the fluorescence signal between the head and tail, thus classifying the heads as isolated nucleoids. The presence of hedgehog comets indicates cells in the early stages of apoptosis (Hartmann et al., 2003). These comets can be originated from koilocytes, which were frequently observed in histopathology analyses. Therefore, koilocytes are cells destined for apoptosis, leading to the release of BPV virions.

The clastogenicity observed is the result of the synergic action of the E5, E6, and E7 oncoproteins, which induce entry into the S phase. The E6 oncoprotein of BPV promotes p53 downregulation, as well as inactivation of E6-E6AP complex formation (Potocki et al., 2014). The inactivation of p53 is related to chromosome instability, DNA methylation changes, and oxidative stress, which leads to cellular mutations (Potocki et al., 2014).

The BPV oncoproteins also function in the pro and anti-oxidative balance of the host cell, thus affecting redox balance, which leads to DNA damage, as indicated by the clastogenicity results. Potocki et al. (2014) reported a $20 \%$ reduction in the membrane potential of mitochondria from fibroblasts infected with BPV, which resulted in the activation of anaerobic glycolysis (Warburg effect). The detection of E7 and L1 in the present study suggests that BPV induces histopathological alterations in both epithelium and connective tissue, including fibroblastic transformation. BPV can also develop a microenvironment with alterations in redox balance, which increases oxidative stress. This can lead to anaerobic glycolysis, in which the BPV oncoproteins 
induce cell proliferation. E6 impacts the host repair system by downregulating and inactivating p53. These combined responses lead to pleotropic changes due the accumulation of mutations, which results in cancer.

After malignant transformation, BPV oncoproteins activate the Ras and NF-KB pathways, leading to the induction of reactive oxygen species (ROS) production in epithelial cells. These ROS are transported to fibroblasts by MCT4 membrane transporters. In response, fibroblasts produce L-lactate and ketone bodies, which are transported to epithelial cells to direct the metabolism to anaerobic glycolysis. This situation establishes a synergism between the epithelium and stroma to maintain energetic intake, which is necessary for tumor growth (Martinez-Outschoorn et al., 2011). In summary, few studies have contributed to the understanding of BPV infection and related oncogenesis. It is known that BPVs are responsible for $12 \%$ of total neoplasias (Wang and Roden, 2013). BPV is a model for HPV, which is responsible for $5 \%$ of all lethal cases of cancer in the world (Wang and Roden, 2013). Here, we demonstrate that BPV infection in fibroblasts is associated with cellular transformation. The clastogenicity results demonstrating genomic instability indicates the development of a tumor microenvironment in which there is a synergistic participation of both the epithelium and connective tissue to guarantee the energetic supply necessary for tumor growth.

\section{Conflicts of interest}

The authors declare no conflict of interest.

\section{ACKNOWLEDGMENTS}

We thank Magna Soares for academic support, as well as Conselho Nacional de Desenvolvimento Científico e Tecnológico (CNPq), Coordenação de Aperfeiçoamento de Pessoal de Nível Superior (CAPES), and Fundação Butantan for financial support.

\section{REFERENCES}

Araldi RP, Melo TC, Diniz N, Carvalho R, et al. (2013). Bovine papillomavirus clastogenic effect analyzed in comet assay. BioMed Res. Int. 2013: 630683.

Araldi RP, Giovanni DN, Melo TC, Diniz N, et al. (2014). Bovine papillomavirus isolation by ultracentrifugation. J. Virol. Methods 208: 119-124.

Baker CC, Phelps WC, Lindgren V, Braun MJ, et al. (1987). Structural and transcriptional analysis of human papillomavirus type 16 sequences in cervical carcinoma cell lines. J. Virol. 61: 962-971.

Betiol JC, Kignel S, Trsitão W, Arruda AC, et al. (2012). HPV 18 prevalence in oral mucosa diagnosed with verrucous leukoplakia: cytological and molecular analysis. J. Clin. Pathol. 65: 769-770.

Bianchi MV, Casagrande RA, Watanabe TTN, Wouters ATB, et al. (2012). Canine papillomatosis: a retrospective study of 24 cases (2001-2011) and immunohistochemical characterization. Pesq. Vet. Bras. 32: 653-657.

Bocaneti F, Altamura G, Corteggio A, Velescu E, et al. (2014). Bovine papillomavirus: new insights into an old disease. Transbound Emerg. Dis. 1-10.

Burnett S, Jareborg N and DiMaio D (1992). Localization of bovine papillomavirus type 1 E5 protein to transformed basal keratinocytes and permissive differentiated cells in fibropapilloma tissue. Proc. Natl. Acad. Sci. U. S. A. 89: 5665-5669.

Calinisan JH, Chan SR, King A and Chan P (2002). Human papillomavirus and blastocyst apoptosis. J. Assist. Reprod. Genet. 19: $132-136$.

Campo MS (1997). Vaccination against papillomavirus in cattle. Clin. Dermatol. 15: 275-283.

Day PM, Lowy DR and Schiller JT (2003). Papillomaviruses infect cells via a clathrin-dependent pathway. Virology 307: 1-11.

Fernandes MC, Ribeiro MG, Fedato FP, Paes AC, et al. (2009). Papilomatosis in dogs: literature review and study of twelve cases. Semina Ciências Agrárias 30: 215-224.

Hartmann A, Agurell E, Beevers C, Brendler-Schwaab S, et al. (2003). Recommendations for conducting the in vivo alkaline 
comet assay. 4th International Comet Assay Workshop. Mutagenesis 18: 45-51.

Kim K, Garner-Hamrick PA, Fisher C, Lee D, et al. (2003). Methylation patterns of papillomavirus DNA, its influence on E2 function, and implications in viral infection. J. Virol. 77: 12450-12459.

Krawczyk E, Suprynowicz FA, Liu X, Dai Y, et al. (2008). Koilocytosis: a cooperative interaction between the human papillomavirus E5 and E6 oncoproteins. Am. J. Pathol. 173: 682-688.

Lancaster W and Olson C (1982). Animal papillomaviruses. Microbiol. Rev. 46: 191-207.

Leto Md, Santos-Júnior GF, Porro AM and Tomimori J (2011). Human papillomavirus infection: etiopathogenesis, molecular biology and clinical manifestations. An. Bras. Dermatol. 86: 306-317.

Love AJ, Chapman SN, Matic S, Noris E, et al. (2012). In planta production of a candidate vaccine against bovine papillomavirus type 1. Planta 236: 1305-1313.

Lunardi M, Alcântara BK, Otonel RA, Rodrigues WB, et al. (2013). Bovine papillomavirus type 13 DNA in equine sarcoids. J. Clin. Microbiol. 51: 2167-2171.

Martelli-Marzagão F, Yamashiro AS, Ogawa MM, Santos-Júnior GF, et al. (2010). Caracterização clínica e histopatológica e tipagem do papilomavírus humano das verrugas vulgares nos receptores de transplante renal. An. Bras. Dermatol. 85: 743-746.

Martens A, De Moor A, Demeulemeester J and Ducatelle R (2000). Histopathological characteristics of five clinical types of equine sarcoid. Res. Vet. Sci. 69: 295-300.

Martinez-Outschoorn UE, Pavlides S, Howell A, Pestell RG, et al. (2011). Stromal-epithelial metabolic coupling in cancer: integrating autophagy and metabolism in the tumor microenvironment. Int. J. Biochem. Cell Biol. 43: 1045-1051.

McBride AA, Sakakibara N, Stepp WH and Jang MK (2012). Hitchhiking on host chromatin: how papillomaviruses persist. Biochim. Biophys. Acta 1819: 820-825.

Melo TC, Diniz N, Campos SR, Ferraz OP, et al. (2011). Cytogenetic studies in peripheral blood of bovines afflicted by papillomatosis. Vet. Comp. Oncol. 9: 269-274.

Melo TC, Carvalho RF, Mazzucchelli-de-Souza J, Diniz N, et al. (2014). Phylogenetic classification and clinical aspects of a new putative Deltapapillomavirus associated with skin lesions in cattle. Genet. Mol. Res. 13: 2458-2469.

Moody CA and Laimins LA (2010). Human papillomavirus oncoproteins: pathways to transformation. Nat. Rev. Cancer 10: 550-560.

Nasir L and Reid SW (1999). Bovine papillomaviral gene expression in equine sarcoid tumours. Virus Res. 61: 171-175.

Potocki L, Lewinska A, Klukowska-Rötzler J, Bielak-Zmijewska A, et al. (2014). Sarcoid-derived fibroblasts: links between genomic instability, energy metabolism and senescence. Biochimie 97: 163-172.

Rashad AL and Evans CA (1967). Histologic features of virus-rich and virus-poor Shope papillomas of cottontail rabbits. Cancer Res. 27: 1855-1860.

Rogovskyy AS, Baszler TV, Bradway DS, Bruning DL, et al. (2012). A novel papillomavirus isolated from proliferative skin lesions of a wild American beaver (Castor canadensis). J. Vet. Diagn. Invest. 24: 750-754.

Roperto S, Comazzi S, Ciusani E, Paolini F, et al. (2011). PBMCs are additional sites of productive infection of bovine papillomavirus type 2. J. Gen. Virol. 92: 1787-1794.

Roperto S, Borzacchiello G, Esposito I, Riccardi M, et al. (2012). Productive infection of bovine papillomavirus type 2 in the placenta of pregnant cows affected with urinary bladder tumors. PLoS One 7: e33569.

Stocco dos Santos RC, Lindsey CJ, Ferraz OP, Pinto JR, et al. (1998). Bovine papillomavirus transmission and chromosomal aberrations: an experimental model. J. Gen. Virol. 79: 2127-2135.

Teifke JP, Kidney BA, Löhr CV and Yager JA (2003). Detection of papillomavirus-DNA in mesenchymal tumour cells and not in the hyperplastic epithelium of feline sarcoids. Vet. Dermatol. 14: 47-56.

Tomita Y, Ogawa T, Jin Z and Shirasawa H (2007). Genus specific features of bovine papillomavirus E6, E7, E5 and E8 proteins. Virus Res. 124: 231-236.

Wang JW and Roden RB (2013). L2, the minor capsid protein of papillomavirus. Virology 445: 175-186.

White EA and Howley PM (2013). Proteomic approaches to the study of papillomavirus - host interactions. Virology 435: 57-69.

Williams JH, van Dyk E, Nel PJ, Lane E, et al. (2011). Pathology and immunohistochemistry of papillomavirus-associated cutaneous lesions in Cape mountain zebra, giraffe, sable antelope and African buffalo in South Africa. J. S. Afr. Vet. Assoc. 82: 97-106.

Yaguiu A, Dagli ML, Birgel EH Jr, Alves Reis BC, et al. (2008). Simultaneous presence of bovine papillomavirus and bovine leukemia virus in different bovine tissues: in situ hybridization and cytogenetic analysis. Genet. Mol. Res. 7: 487-497.

Zheng ZM and Baker CC (2006). Papillomavirus genome structure, expression, and post-transcriptional regulation. Front. Biosci. 11: 2286-2302.

Zimmermann H, Degenkolbe R, Bernard HU and O'Connor MJ (1999). The human papillomavirus type 16 E6 oncoprotein can down-regulate p53 activity by targeting the transcriptional coactivator CBP/p300. J. Virol. 73: 6209-6219. 